\title{
Discussion on the Feasibility of nudge in Education
}

\section{Hongyang Liu Lucie Kremenkova*}

Institute of Educational and Social Studies, Palacky University Olomouc, Czech Republic

\section{ARTICLE INFO}

Article history

Received: 1 April 2021

Revised: 7 April 2021

Accepted: 9 April 2021

Published Online: 16 April 2021

Keywords:

Nudge

Education

Decision making

Study

\section{Introduction}

Decisions are everywhere. Whether it is an individual, an enterprise, a political party, or the country, a large number of decisions are required every day. At the macro level, there are what strategy the country chooses and how the government promotes the payment of national pensions. At the micro level, some students choose to spend their spare time for entertainment or study, going to the library or going to the bar after class. The quality of decision-making is related to national development, enterprise success or failure, and personal gains and losses. Then the process of human decision-making is directly affected by their psychological process.

Many academic problems are caused by improper behavior of students or teachers. If students like instant happiness and be unwilling to think about their future,

\section{ABSTRACT}

This paper first introduces the definition of nudge, the history of nudge and the advantages of nudge. This concept means a relatively subtle policy shift that encourages people to make decisions that are in their broad self-interest. It relies on insights from behavioral science, and when used ethically, it can be very helpful. Subsequently, the research results of the nudge method in public decision-making fields such as health and environmental protection are listed, inferring the feasibility of nudge method in the field of education, especially learners' specific behavior decision. Then according to the classification of the nudge method by the decision-making system, the research on nudge used in the education field is enumerated. It demonstrates that nudge still has a lot of room for expansion in the field of education.

they will only spend very little time on their studies. If the teachers neglect to guide the students and only busy with their own research, it will also make it difficult for students to graduate.

How to deal with these problems? Paternalism advocates believe that most students will choose immediate gratification in the choice of delayed gratification and immediate gratification, therefore, they should be forced to discipline, through artificially limit their entertainment time and monitor their learning progress to avoid the academic problems mentioned above. What's more, in China, in order to let children quit internet addiction, they make their children to participate in the so-called "Internet addiction training camp" and to accept "electric shock therapy". According to reports, because of this ignorance, one child have been killed in the training camp (Jiang Qiping, $2009)^{[1]}$. In today's society, especially in most democratic

*Corresponding Author:

Lucie Kremenkova

Institute of Educational and Social Studies, Palacky University Olomouc, Czech Republic;

E-mail: lucie.kremenkova@gmail.com 
countries in the world, this approach will be considered ignorant, backward and invalid.

Advocators of liberalism disagree with compulsory intervention in individual behavior, believing that students' learning is active, and people's autonomy and freedom of choice are inalienable, the "invisible hand" will be repaired rationally, and managers do not know themselves better than individuals. It is also easy to make mistakes to enforce individual behaviors.

This dispute between patriarchal and liberal management methods exists in many areas of social management. However, the effects of the two management methods are usually not very good, because the former is offensive and the latter is indulgent. When the two argue with each other, behavioral scientists (including psychologists and behaveioral economists engaged in behavioral decision-making research) think that there is actually a third way. Instead of entangled in the debate of ideas, they gave a flexible approach between the two ${ }^{[2] .}$

The third path proposed by behavioral decision-makers is called "nudge" (Thaler \& Sunstein, 2008) ${ }^{[3]}$. Nudge does not prohibit any options, does not restrict the freedom of choice, nor does it resort to commands and guidance, but by appropriately changing the choice architecture faced by people, making people's behavior choices change as expected.

The success or failure of studies often involves various large and small decisions of students or teachers. Given that nudge has achieved research results in many fields, for example, government intervention in environmental protection, pension payment, and promotion of healthy diet, the researchers thinks that schools can create nudge conditions to promote the development of education.

As an effective practice of behavioral economics in public policy, nudge can also explain some educational phenomenas in reality. For example, the prospect theory describes the important role of the initial reference frame when people face risks, that is, they are willing to take risks when facing losses, but are more conservative when they are about to make profits. In the intergenerational transmission of education, some researchers have found that parents with only high school degrees have much lower motivation for their children to enter higher education institutions than parents with university degrees, this is because the education level of the parents themselves will become the reference standard for the education level of the children(Louis Lévy-Garboua, 2007) ${ }^{[4]}$.

Therefore, this article will explore the feasibility of nudge method in promoting education. It not only has low cost, high efficiency and great benefit, but also does not restrict the individual's freedom of choice. "nudge" and its characteristics for peoples' decision-making. In order to make it better used in education, in this part, on the contrary, the construct of "nudge" will be presented in more detail, either from a theoretical or applied perspective.

\subsection{The Government's Application of Nudge Method}

If we focus on the concept of "nudge" in a very brief historical discourse (to be more precise on a few historical examples), we can mention $17^{\text {th }}$ century. At that time the food sources of the entire European region mainly depended on wheat or corn. Due to weather and other factors, its annual output sometimes drops dramatically, leading to famines in large areas and killing countless people. At the same time, another starchy plant (potatoes) that is drought-tolerant and easy to grow has been resisted by churches and farmers due to its completely different planting methods (planted underground) and dietary tastes. Even legislative compulsion cannot effectively encourage farmers to plant potatoes.

In order to popularize potato cultivation, the King of Prussia adopted a simple and ingenious method. He planted potatoes in his royal garden and showed his love for potatoes. This practice changed the original attitude of farmers to scorn potatoes, promoted the widespread cultivation of potatoes, reduced famine in Europe, and saved many lives (Halpern, 2015) ${ }^{[5]}$.

At the beginning of the 20th century, the idea of nudge was also put into practice in public transportation and other fields. Before 1921, there were no signs of lanes and directions on the road, which made the roads often congested and crashed. In 1921, the British first drew white guide lines at the turn of the road to guide vehicles in the correct position. This measure of providing visual reference and feedback effectively reduced the incidence of traffic accidents and has been used today.

The great interest of government departments in nudge research has also promoted the development of nudge research. In 2010, the British government first established a think tank (The Behavioral Insights Team, also known as The Nudge Unit) composed mainly of behavioral scientists, hoping to help the government better formulate and implement policies through nudge methods.

In just a few years, the team has used the nudge method to help the government achieve remarkable results in promoting economic development and environmental protection, and improving the health, education and happiness 
of residents (Behavioural Insights Team, 2015) ${ }^{[6]}$.

In 2015, the then U.S. President Barack Obama also issued a presidential executive order, advocating that various government departments in the United States incorporate behavioral science theories and methods when formulating policies to better serve the American people.

At the same time, the United States has also established its own Social and Behavioral Sciences Team, and has achieved significant results in promoting pension savings and improving residents' health and education (Social and Behavioral Sciences Team, 2015) $)^{[7]}$.

In addition, the World Bank also emphasized the important role of psychology and behavioral science methods in policy formulation and promotion of social development in the "World Development Report: Thinking, Society, and Behavior" in 2015, and concluded that the nudge method can make measures and effects on issues such as eliminating poverty, health promotion, and response to climate change (World Bank, 2015) ${ }^{[8]}$.

In recent years, the research results of nudge have increased year by year, and the successful application of nudge method in various fields has attracted much attention (Benartzi et al., 2017) ${ }^{[9]}$. In 2017, Professor Thaler, the pioneer and advocator of nudge research, was awarded the Nobel Prize in Economics, which further promoted the rise of nudge research.

\subsection{The Principle of Nudge}

Psychologists believe that human judgment and decision-making usually involve two major cognitive systems: a heuristic system based on intuition (system 1) and an analytical system based on reason (system 2) (Kahneman, $2011)^{[10]}$.

When people deal with familiar things, system 1 reacts much faster than system 2. System 1, whose operation is unconscious and fast, completely under autonomous control, and cannot be shut down. The self-control of the person in charge of system 2, which is a lossy system with limited capacity. When the task is too difficult, system 2 will give up. From the perspective of human brain evolution, System 1 was formed much earlier than System 2.

Because of this, people often encounter difficulties when facing complex and major decision-making issues, and cannot make decisions that conform to their own wishes and well-being. At this time, nudge becomes a necessary decision-making and behavioral intervention.

Nudge is an intervention method that helps people make decisions that are beneficial to themself without coercive means or rigid rules on the basis of acknowledging the limited rationality of people (Thaler \& Sunstein, 2008) ${ }^{[3]}$.

For example, for most college students, they are used to turning on the computer and starting to browsing the web, watching videos, playing games, etc. Although they know that their studies are very heavy, their homework is up to the deadline, they will still succumb to their desire for instant gratification. This is because their instant gratification behaviors such as playing games and watching videos are controlled by System 1, which makes people make habitual behaviors very quickly and instinctively with pleasent emotions. The other rational voice, "I need to study hard", is controlled by System 2, which has very limited capacity and requires human subjective effort to maintain, and the joy of delaying gratification like learning is not obvious compared with entertainment. Therefore, reason is often suppressed by emotion.

In addition, System 2 sometimes will become an accomplice of System 1. When you make the behavior controlled by System 1, System 2 will abandon the previous idea of "studying hard" and turn to find reasons for your academic procrastination. Therefore, for the habits of most college students, what methods do we have to induce them to learn without using coercive means? Promoting students' learning behavior by inducing students' system 1 is one of the practice of nudge method in the field of education.

\subsection{Nudge Research Fields}

Psychologists have conducted nudge research in many fields. These studies all involve promoting individuals to make decisions that are beneficial to them over a long period of time rather than immediate gratification.

Some researchers (He Guibing, 2018) search for articles containing the word "nudge" on the web of science, and then filter them through layers, 84 empirical research articles were obtained. In these studies, the areas that nudge research focuses on can be grouped into 6 categories: Health, environmental protection, social security, politics and economy, education and charity ${ }^{[11]}$.

Among them, the number of researches in the health field is the largest, exceeding half of the search results, then followed by the environmental protection field. Among the six major fields, the number of education fields is very small, only three, including interventions in college enrollment and graduation rates, and participation rates in The Free Application for Federal Student Aid (FAFSA) applications.

Overview of the above research fields and research content can be seen that nudge has achieved considerable results in different research fields. There is one thing in common in so many fields of research. That is, all nudge studies are verifying whether those nudge variables can increase the probability of subjects' expected behavior. 
In summary, although nudge has achieved good research results in many aspects, the number of applied research in education is relatively small, then there is even less research on improving students' academic performance. Therefore, the research of nudge in education still has much room for exploration.

\section{Nudge Research's Exploration in the Field of Education}

To start research in the field of education, researchers must first answer some questions:

(1) What education-related goals are we going to use the nudge method to achieve?

(2) Who might be the decision makers?

(3) What factors will decision-makers base on to make decisions?

Researchers try to answer these questions based on the elements of the decision system model (see Figure 1).

Decision-making systems generally include decision makers, information, decision options, decision procedures, decision environment, decision goals and other components (Sobesky et al., 1994) ${ }^{[12]}$. Therefore, the exploration of nudge in the field of education will also be carried out around this decision system model.

According to the decision-making system model, researchers can start with the elements. On the basis of achieving specific goals, the following classifications can be made.

\subsection{The Nudge Method for Decision Makers}

There are many decision makers involved in the education field, including students, teachers, school administrators, educational institutions, parents and the whole society. Decision makers are the source of decision-making, and changes in their mental state will have an impact on the outcome of decision-making.

There have been many nudge methods for decision makers in the past. For example, psychological priming (such as asking about the time, place and method of behavior to enhance the tendency to perform the behavior, and using irrelevant stimuli to initiate the behavior tendency), pre-commitment (improve the decision maker's pre-commitment to a specific behavior), setting up mental accounts (such as setting up specific expenditure or income accounts and account linkages to affect consumption or savings), anticipating errors (improve fault tolerance), etc.

Researcher needs to confirm the decision makers firstly. If researchers target college students, then further the specific behaviors that need improvement. For example, increasing the reading duration of college students, reducing the procrastination behavior, and controlling the excessive indulgence of them, etc.

\subsection{Nudge Method for Decision Information}

Individuals rely on information for any decision. The factors that affect the degree of information dependence include the type and quantity of information, the way to highlight important information, and the difficulty of obtaining information. The operation of information includes information disclosure, highlighting, visualization, redundancy, warning, etc. Researchers can achieve the purpose of intervention by manipulating the expression, frequency, and availability of information.

For example, in the United States, sending SMS reminders of university application deadlines for low-income students has brought a considerable increase in application and acceptance rates (Castleman et al., 2015) ${ }^{[13]}$.

Researchers can group college students, for instance, into two groups to let them complete a paper independently. The desktop icons of the laptops of the subjects in the

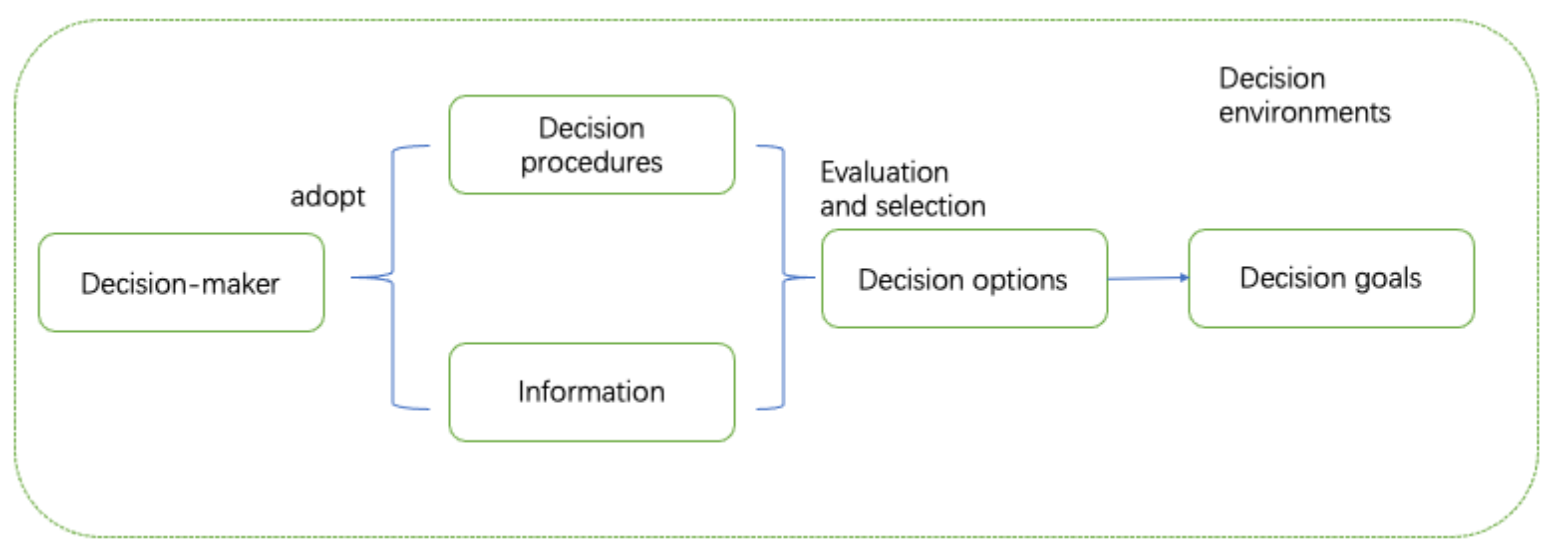

Figure 1. Decision system model (He Guibing, Li Shu, \& Liang Zhuyuan, 2018) ${ }^{[1]}$ 
experimental group were cleared, leaving only the icons of the papers to be completed, then the laptops of the control group did not require any operation. Researchers can compare their status in completing tasks.

\subsection{Nudge Method for Decision Options}

Factors such as the expression of decision options, option structure, and associated incentives will affect the preferences of decision makers.

We can manipulate the way information is expressed. Positive and negative frame wording, for example, showing or hiding opportunity cost, and changing time expression, etc. Researchers can also manipulate the option structure, such as structural characterization of options, changing the order of options, "forced selection" design, reducing dimensions (reserving a small number of important dimensions in screening), reducing options (only providing a few important options), changing default options, providing intermediate options, etc. Nudge methods for option incentives include: increasing or reducing the cost (or benefit) and difficulty, implementation of specific options, highlighting specific incentives, binding commitments (binding specific behaviors with other behaviors that are determined to occur or are determined not to occur), self prohibition (self-blocking of channels for specific actions), etc.

In the field of education, researchers can try to make the participates more convenient to use the school's educational resources to make the subjects more willing to spend more time studying instead of entertainment.

\subsection{Nudge Method for Decision Procedures}

Because of the complexity, multidimensionality and ambiguity of real decision-making, the process of decision-makers is full of complexity and uncertainty. In order to enable decision-makers to make better decisions, researchers can provide assistance in decision-making procedures.

Researchers can help participants simplify decision-making procedures, provide intelligent decision-making assistance, set cooling-off periods (reserve opportunities for modification and remorse), and postpone decision-making, etc.

In order to allow university teachers and students, for instance, to spend more time on academic reading, researchers can try to make teachers and students more exposed to the information in the school library (For example, let teachers and students choose to post a promotional paper with the website or a QR code of the school library on the bedside to remind them to read.).

\subsection{Nudge Method for Decision Environment}

Usually, the environment, including social environment and physical environment, contains many reference factors and behavior inducers, therefore, the environment in which the decision makers live can affect their choices. Researchers can guide decision makers to social norms, for example, providing the choice that most of people decide to. Then researches can also help decision makers look at the consequences of other people's choice to affect their decision. Studies have found that in elementary school classes, the unity atmosphere of the class has a significant positive predictive effect on students' math performance; the conflict atmosphere of the class has a significant negative predictive effect on students' math performance (Goh et al., 1996) ${ }^{[14]}$.Although there are many reasons for this predictive effect, it is very likely that the united class atmosphere makes students spend more time on academics is one of the very important factors.

\section{Conclusion}

Nudge's research has achieved considerable results in many public policy areas. However, in the field of education, there is still a lot of room for development. This article aims to explore whether the nudge method can be used in the field of education research. By classifying the Nudge method according to the decision-making system model, some possible research ideas are listed.

In terms of theory, this article expands the research scope of nudge, so that nudge can be useful in cultivating citizens' good study habits in addition to cultivating citizens' healthy living habits or environmental protection behaviors.

In practice, the nudge method has the advantages of low cost, high efficiency, and high autonomy. Nudge can help people improve their study habits without forcing others, it can be combined with education and training methods to improve people's ability to make good decisions.

In reality, many students consciously know that they need to study hard, however, they are unable to extricate themselves from the abyss of academic procrastination, because system 1 succumbed to the temptation of instant gratification. In this case, students can create a nudge environment to let themselves to have more academic behaviors. This behavior of creating nudge conditions for oneself can temporarily be called self-nudge. If it is to motivate students to promote more academic behavior, self-nudge will be a main research direction.

The limitation of this article is that the exploration of

DOI: https://doi.org/10.26549/jetm.v5i1.6760 
nudge in education only stays at the stage of imagination, and there is no clear definition of the evaluation indicators of good learning habits. In future empirical research, it is necessary to define the indicators for subjects to improve their learning habits.

\section{References}

[1] Jiang Qiping. Internet addiction treatment is pseudoscience[J]. Internet Weekly, 2009(019), 6-6.

[2] He Guibing. Nudge: The Third Way[J]. Management Vision,2016(06):101-105.

[3] Thaler, R. H., Sunstein, et al. Nudge: improving decisions about health, wealth and happiness[M]. London: Yale University Press, 2008.

[4] Louis Lévy-Garboua, Page, L., Montmarquette, C.. Aspiration levels and educational choices: an experimental study[J]. Economics of Education Review, 2007,26(06):747-757.

[5] Mahmoud, Omar. Inside the nudge unit: how small changes can make a big difference[J]. International journal of market research, 2016, 58(1):155-157.

[6] Luca M, Rooney P. Behavioural Insights Team (B) [J]. 2015. http://www.behaviouralinsights.co.uk/ wpcontent/uploads/2015/07/BIT_Update-Report-Final-2013-2015.pdf.

[7] Social and Behavioral Sciences Team. Social and Behavioral Sciences Team annual report[R]. Wash- ington, DC: National Science and Technology Council, Executive Office of the President. Retrieved from https://www.dol.gov/asp/evaluation/reports/ sbst_2015_annual_report_final_9_14_15.pdf.

[8] World Bank. World development report 2015: Mind, society, and behavior[R]. Washington, DC: World Bank, 2015.

[9] Benartzi S, Beshears J, Milkman K L, et al. Should Governments Invest More in Nudging?[J]. Psychological Science, 2017, 28(8):956797617702501.

[10] Kahneman, D. Thinking, fast and slow[M]. Farrar: Straus and Giroux, 2011.

[11] He Guibing, Li Shu, \& Liang Zhuyuan. Use the small to make the big: behavioral decision-making boosts social development[J]. Psychological News, 2018,50(8):18-19.

[12] Sobesky, M., Michelet, C., Thomas, R., et al. Decision making system[J]. Clin Comput, 1994,6(23), 20-26.

[13] Castleman B L , Page L C . Summer nudging: Can personalized text messages and peer mentor outreach increase college going among low-income high school graduates?[J]. Journal of Economic Behavior \& Organization, 2015(115):144-160.

[14] Goh S, Fraser B J. Classroom Climate and Student Outcomes in Primary Mathematics[J]. Index, 1996. 